\title{
The chloroplast genome sequence of the green alga Leptosira terrestris: multiple losses of the inverted repeat and extensive genome rearrangements within the Trebouxiophyceae Jean-Charles de Cambiaire, Christian Otis, Monique Turmel and Claude Lemieux*
}

Address: Département de biochimie et de microbiologie, Université Laval, Québec, Canada

Email: Jean-Charles de Cambiaire - jean-charles.de_cambiaire@rsvs.ulaval.ca; Christian Otis - christian.otis@rsvs.ulaval.ca; Monique Turmel - monique.turmel@ rsvs.ulaval.ca; Claude Lemieux* - claude.lemieux@rsvs.ulaval.ca

* Corresponding author

Published: 4 July 2007

BMC Genomics 2007, 8:213 doi:|0.||86/|47|-2|64-8-2/3
Received: 21 March 2007

Accepted: 4 July 2007

This article is available from: http://www.biomedcentral.com/147I-2164/8/213

(c) 2007 de Cambiaire et al; licensee BioMed Central Ltd.

This is an Open Access article distributed under the terms of the Creative Commons Attribution License (http://creativecommons.org/licenses/by/2.0), which permits unrestricted use, distribution, and reproduction in any medium, provided the original work is properly cited.

\begin{abstract}
Background: In the Chlorophyta - the green algal phylum comprising the classes Prasinophyceae, Ulvophyceae, Trebouxiophyceae and Chlorophyceae - the chloroplast genome displays a highly variable architecture. While chlorophycean chloroplast DNAs (cPDNAs) deviate considerably from the ancestral pattern described for the prasinophyte Nephroselmis olivacea, the degree of remodelling sustained by the two ulvophyte cpDNAs completely sequenced to date is intermediate relative to those observed for chlorophycean and trebouxiophyte cpDNAs. Chlorella vulgaris (Chlorellales) is currently the only photosynthetic trebouxiophyte whose complete cpDNA sequence has been reported. To gain insights into the evolutionary trends of the chloroplast genome in the Trebouxiophyceae, we sequenced cpDNA from the filamentous alga Leptosira terrestris (Ctenocladales).
\end{abstract}

Results: The 195,08I-bp Leptosira chloroplast genome resembles the 150,613-bp Chlorella genome in lacking a large inverted repeat (IR) but differs greatly in gene order. Six of the conserved genes present in Chlorella cpDNA are missing from the Leptosira gene repertoire. The 106 conserved genes, four introns and II free standing open reading frames (ORFs) account for $48.3 \%$ of the genome sequence. This is the lowest gene density yet observed among chlorophyte cpDNAs. Contrary to the situation in Chlorella but similar to that in the chlorophycean Scenedesmus obliquus, the gene distribution is highly biased over the two DNA strands in Leptosira. Nine genes, compared to only three in Chlorella, have significantly expanded coding regions relative to their homologues in ancestral-type green algal cpDNAs. As observed in chlorophycean genomes, the rpoB gene is fragmented into two ORFs. Short repeats account for $5.1 \%$ of the Leptosira genome sequence and are present mainly in intergenic regions.

Conclusion: Our results highlight the great plasticity of the chloroplast genome in the Trebouxiophyceae and indicate that the IR was lost on at least two separate occasions. The intriguing similarities of the derived features exhibited by Leptosira cpDNA and its chlorophycean counterparts suggest that the same evolutionary forces shaped the IR-lacking chloroplast genomes in these two algal lineages. 


\section{Background}

All chloroplasts of photosynthetic eukaryotes inherited from their cyanobacterial ancestors a reduced genome that encodes part of the genes essential for their biogenesis. The chloroplast genome has been studied in various algal lineages, particularly in the green algal/land plant lineage (Viridiplantae) for which the number of complete chloroplast DNA (cpDNA) sequences available in public databases increases steadily. Comparative analyses of the latter genome sequences highlight distinct evolutionary trends in the Streptophyta and the Chlorophyta. In the Streptophyta, the division comprising the green algae from the class Charophyceae and all land plants, the chloroplast genome shows remarkable conservation in overall structure, gene content, gene order and intron content $[1,2]$. In contrast, considerable fluidity in chloroplast genome organization is the hallmark of the Chlorophyta, the division comprising the four remaining green algal classes (Prasinophyceae, Ulvophyceae, Trebouxiophyceae and Chlorophyceae).

The chloroplast genomes from members of the Ulvophyceae (Oltmannsiellopsis viridis [3] and Pseudendoclonium akinetum [4]), Trebouxiophyceae (Chlorella vulgaris [5] and the non-photosynthetic alga Helicosporidium sp. [6]) and Chlorophyceae (Stigeoclonium helveticum [7], Scenedesmus obliquus [8] and Chlamydomonas reinhardtii [9]) display various patterns of divergence compared to the ancestral pattern described for a representative of the Prasinophyceae (Nephroselmis olivacea [10]). The cpDNA of this prasinophyte resembles most of its streptophyte homologues in displaying small and large single-copy (SSC and LSC) regions that are separated from one another by two identical inverted repeat regions (IR). Moreover, the set of genes encoded by each of these three genomic regions is almost identical in Nephroselmis and streptophyte cpDNAs. Moderate deviations from this ancestral-type architecture are seen in the two earliest-diverging lineages of the Ulvophyceae (the orders Oltmannsiellopsidales and Ulotrichales), supporting the hypothesis that a dozen genes were transferred from the LSC to the SSC region and that the rRNA operon in the IR was altered in orientation very early during the evolution of ulvophytes [3]. Although the cpDNAs of the chlorophycean green algae Chlamydomonas and Scenedesmus have also retained a quadripartite structure, the single-copy regions of these genomes differ extensively in gene content and both genomes deviate radically from the ancestral gene partitioning pattern [8]. The chloroplast genomes of Chlorella [5] and Stigeoclonium [7] as well as the plastid genome of Helicosporidium [6] lack an IR, indicating that this repeat was lost independently in the Trebouxiophyceae and Chlorophyceae. Considering that loss of the IR is often correlated with gene rearrangements $[11,12]$, it is noteworthy that the IR-lacking cpDNA of the trebouxiophyte
Chlorella retains an almost intact pattern of ancestral gene partitioning [3].

In Helicosporidium and the three lineages of chlorophycean green algae examined, remodelling of plastid/chloroplast genome architecture was accompanied by the formation of long blocks of consecutive genes on the same DNA strand [6-8,13]. For the Stigeoclonium and Helicosporidium genomes, the pattern of gene distribution between the two DNA strands was found to be correlated with a bias in base composition along each strand, allowing the identification of a potential origin of replication $[6,7]$.

The cpDNAs of ulvophyte, trebouxiophyte and chlorophycean (UTC) green algae also underwent erosion of ancestral gene clusters, many gene losses, proliferation of short dispersed repeats and introns as well as expansions of intergenic spacers and proteins-coding genes $[3,7]$. All photosynthetic genes were lost in the lineage leading to the heterotrophic trebouxiophyte Helicosporidium, giving rise to an extremely compact genome greatly reduced in both size and gene content [6]. In addition, three expanded genes in chlorophycean green algal cpDNAs were split into two distinct open reading frames (ORFs); this is the case for the $r p o B$ genes of Stigeoclonium, Scenedesmus and Chlamydomonas, for rps2 of the latter two algae and for rpoC1 of Chlamydomonas [7]. While chlorophycean green algal cpDNAs were most affected by the abovementioned structural changes, their ulvophyte homologues were altered to an intermediate degree relative to the chlorophycean and Chlorella genomes $[3,4]$.

To gain insights into the evolutionary trends of the chloroplast genome in the Trebouxiophyceae and to elucidate the relationships among the various lineages of this class, we undertook the complete sequencing of cpDNA from phototrophic trebouxiophytes occupying lineages distinct from that represented by Chlorella and Helicosporidium (Chlorellales). We describe here the chloroplast genome sequence of Leptosira terrestris, a filamentous alga formally named Pleurastrum terrestre [14] and currently thought to belong to the Ctenocladales. Even though this genome resembles its Chlorella homologue in missing an IR, it is considerably shuffled in gene order and displays derived features that were previously observed in ulvophyte and/ or chlorophycean green algal cpDNAs. Our results highlight the great plasticity of the chloroplast genome in the Trebouxiophyceae.

\section{Results \\ Genomic features}

The Leptosira chloroplast genome sequence assembles as a circular molecule of 195,081 bp encoding a total of 106 genes, not counting the intron ORF and the 11 free stand- 
ing ORFs (Figure 1). All genes are present in single copy. Table 1 compares the general features of Leptosira cpDNA with those reported for the eight other chlorophyte cpDNAs completely sequenced to date. With an overall A+T content of $72.7 \%$, the Leptosira genome ranks at the third position, after Helicosporidium plastid DNA and Scenedesmus cpDNA, with respect to the abundance of these bases. The 106 conserved genes, four introns and 11 free standing ORFs of more than 60 codons account for $48.3 \%$ of the total genome sequence of this trebouxiophyte, with the introns representing only $2.3 \%$ of the sequence. This is the lowest coding density among all examined chlorophyte cpDNAs. Intergenic regions have an average size of $981 \mathrm{bp}$, a value slightly higher than those observed for Stigeoclonium (950 bp) and Chlamydomonas (941 bp) cpDNAs. All four introns belong to the group I family.

\section{Gene content and gene expansions}

The chloroplast gene repertoire of Leptosira differs from that of Chlorella by the absence of three protein-coding genes (chlI, ccsA and $y c f 12$ ) and three tRNA genes [trnL(gag), trnS(gga) and $\operatorname{trnT}$ (ggu)]. Although the latter three genes are missing, the set of 28 tRNA species encoded by Leptosira cpDNA is sufficient to read all codons present in this genome. The $\operatorname{trnL}$ (gag) and $\operatorname{trn} T$ (ggu) genes are also missing in the two ulvophyte and three chlorophycean green algal chloroplast genomes sequenced so far and chll is absent from all three chlorophycean genomes: however, the $\operatorname{css} A$ and $\gamma c f 12$ genes have been retained in all these genomes. Aside from Leptosira, the trnS (gga) gene has been lost from all UTC algal cpDNAs previously investigated, except Chlorella and Stigeoclonium.

As in other UTC algal chloroplast genomes, a small fraction of the genes in Leptosira cpDNA have expanded coding regions relative to their Nephroselmis and streptophyte homologues. Nine genes in the Leptosira genome are more than 50\% larger than their Mesostigma counterparts (cemA, $f t s H, r p l 19, r p o A, r p o B, r p o C 1, r p o C 2, y c f 1$ and $\gamma c f 4) \mathrm{com}-$ pared to only three in Chlorella cpDNA (cemA, ftsH and $y c f 1$ ) [3]. In addition, for the latter three expanded genes, we find a more important expansion factor in Leptosira than in Chlorella.

Like its chlorophycean green algal homologues, the chloroplast $r p o B$ gene of Leptosira consists of two separate ORFs $(r p o B a$ and $r p o B b)$ that are not associated with sequences typical of group I or group II introns (Figure 1). As in Chlamydomonas and Scenedesmus cpDNAs, these ORFs are contiguous in Leptosira cpDNA and are separated by stop codons. Reverse transcriptase-PCR analysis failed to identify a genuine transcript encompassing both the Chlamydomonas rpoBa and $r p o B b$ codingregions [9]; however, distinct transcripts were found to be specific to these
ORFs [9]. This result together with the observation that the Stigeoclonium $r p o B a$ and $r p o B b$ are encoded by different DNA strands and map to separate genomic loci [7] suggest that the two ORFs are transcribed independently. The Chlamydomonas rpoBa and $r p o B b$ are considered to be functional genes, because no chloroplast-targeted RNA polymerase gene could be identified in the nuclear genome of this alga [15]. The fragmentation of $r p o B$ in Leptosira cpDNA and its chlorophycean homologues is reminiscent of the well-known case of $r p o C$ gene fragmentation in cyanobacteria and plastids $(r p o C 1$ and $r p o C 2)$ [16].

Figure 2 shows the results of our comparative sequence analysis of the translated $r p o B$ sequences from Leptosira, the seven other photosynthetic chlorophytes whose chloroplast genome has been scrutinized, and two streptophytes. Regions displaying high sequence divergence and significant heterogeneity in size were identified at the two termini and at 11 internal sites. Some of the variable, internal regions represent insertions that are unique to one or more of the taxa examined. For example, the sequences mapping to three sites are present only in Leptosira, whereas that corresponding to a fourth site is specific to Stigeoclonium. Blast analyses conducted during the course of the present study revealed that the insertion sequence of 390 amino acids at the latter site displays features typical of inteins [17]; this finding was made independently by another laboratory and documented in InBase $[17,18]$ under the accession name She_RPB2. The $r p o B$ genes of Leptosira and of the three chlorophycean green algae are fragmented at the same site, near the junction of a conserved segment of 80 codons and a highly variable region (ranging from 7 to 803 codons in size) found in all taxa.

The 11 ORFs of more than 60 codons that we identified in intergenic regions of Leptosira cpDNA failed to display any similarity with known DNA sequences. All these ORFs differ from the conserved protein-coding genes at the levels of codon usage and their tendency to be richer in $\mathrm{A}+\mathrm{T}$.

\section{Gene distribution between the two DNA strands}

With 78 genes occupying one strand and 28 genes the other strand, the gene distribution over the two DNA strands of the Leptosira genome is highly biased (Figure 1). While a similar bias has been observed for Scenedesmus cpDNA (77 genes on one strand and 26 genes one the other) [8], other completely sequenced chlorophyte cpDNAs display about the same number of genes on the two strands (Figure 3). All 78 Leptosira genes found on the same cpDNA strand, except $\gamma c f 62$ and cemA, are grouped together, forming four separate stretches containing 9 to 24 genes. 


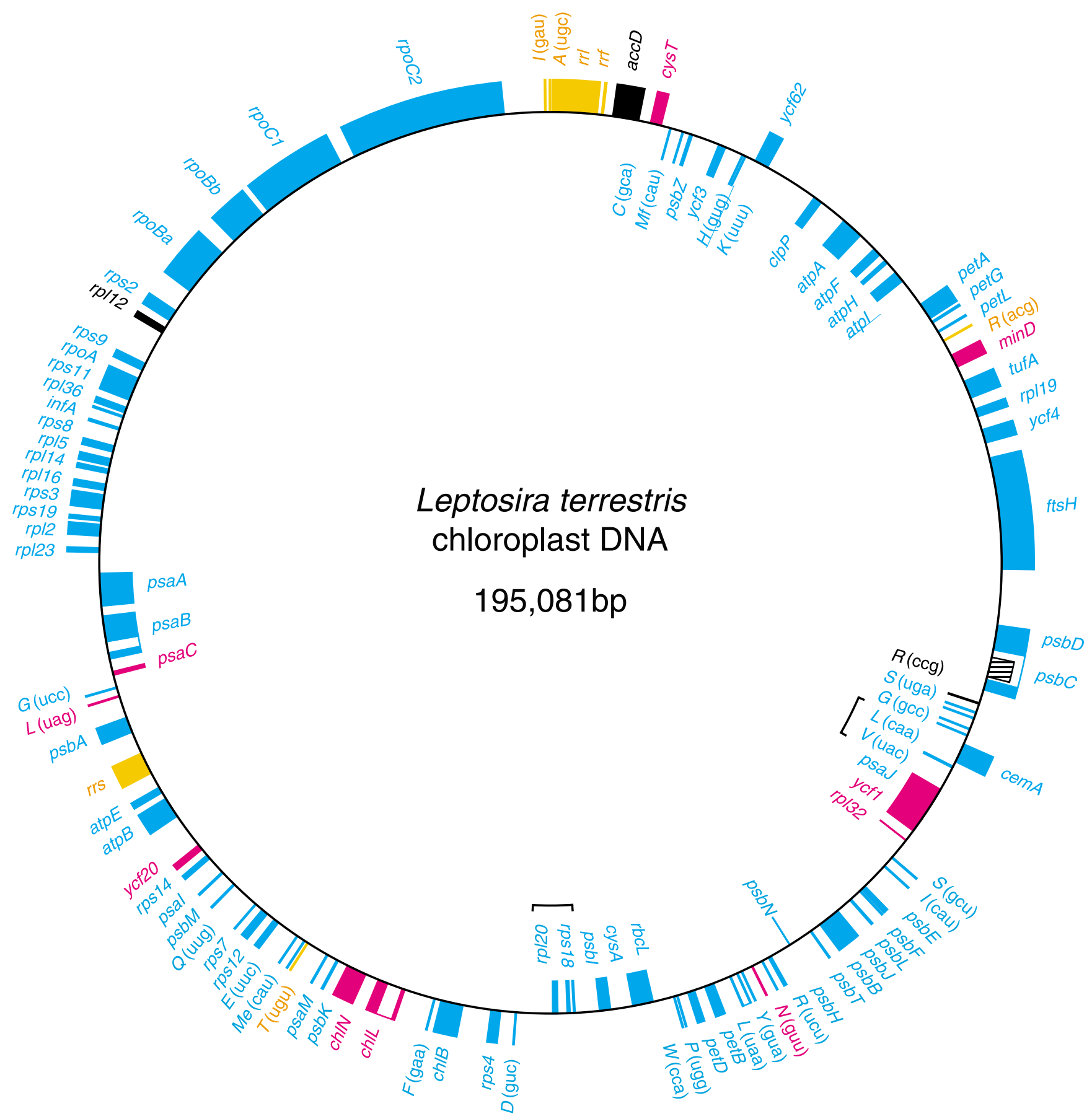

Figure I

Gene map of Leptosira cpDNA. Genes (filled boxes) on the outside of the map are transcribed in a clockwise direction; those on the inside are transcribed counterclockwise. Introns are represented by open boxes and the intron ORF is denoted by a narrow, hatched box. Genes shown in yellow, cyan and magenta map to the IR, LSC and SSC regions of Mesostigma cPDNA. Genes and ORFs absent from Mesostigma cpDNA are shown in black. Brackets denote the gene clusters shared specifically with Chlorella cpDNA. tRNA genes are indicated by the one-letter amino acid code followed by the anticodon in parentheses (Me, elongator methionine; $M f$, initiator methionine). 
Table I: General features of Leptosira and other chlorophyte cpDNAs

\begin{tabular}{|c|c|c|c|c|c|c|c|c|c|}
\hline \multirow[b]{2}{*}{ cpDNA ${ }^{a}$} & \multicolumn{4}{|c|}{ Size } & \multirow[b]{2}{*}{$\mathrm{A}+\mathrm{T}(\%)$} & \multirow[b]{2}{*}{ Coding (\%) ${ }^{b}$} & \multirow[b]{2}{*}{ Genes (no.) ${ }^{c}$} & \multicolumn{2}{|c|}{ Introns } \\
\hline & Total & IR & LSC & SSC & & & & $\mathbf{I}$ & II \\
\hline Nephroselmis (P) & 200,799 & 46,137 & 92,126 & 16,399 & 57.9 & 68.7 & 128 & 0 & 0 \\
\hline Chlorella $(\mathrm{T})$ & 150,613 & $-d$ & $-d$ & $-d$ & 68.4 & 60.9 & 112 & 3 & 0 \\
\hline Leptosira $(\mathrm{T})$ & $|95,08|$ & $-d$ & $-d$ & $-d$ & 72.7 & 48.3 & 106 & 4 & 0 \\
\hline Helicosporidium (T) & 37,454 & $-d$ & $-d$ & $-d$ & 73.1 & 94.9 & 54 & 1 & 0 \\
\hline Oltmannsiellopsis (U) & 151,933 & 18,510 & 33,610 & 81,303 & 59.5 & 59.2 & $104 \mathrm{e}$ & 5 & 0 \\
\hline Pseudendoclonium (U) & 195,867 & 6,039 & $|40,9| 4$ & 42,875 & 62.3 & 62.3 & 105 & 27 & 0 \\
\hline Stigeoclonium (C) & 223,902 & $-d$ & $-d$ & $-d$ & 71.1 & 55.8 & 97 & 16 & 5 \\
\hline Scenedesmus (C) & 161,452 & 12,022 & $72,440^{f}$ & $64,968 \mathrm{~g}$ & 73.1 & 67.2 & 96 & 7 & 2 \\
\hline Chlamydomonas (C) & 203,827 & 22,211 & $81,307^{f}$ & $78,088 \mathrm{~g}$ & 65.5 & 50.1 & 94 & 5 & 2 \\
\hline
\end{tabular}

a The letter in parentheses indicates the chlorophyte lineage: P, Prasinophyceae; T, Trebouxiophyceae; U, Ulvophyceae; C, Chlorophyceae.

b Conserved genes, unique ORFs and introns were considered as coding sequences.

c Genes present in the IR were counted only once. Unique ORFs and intron ORFs were not taken into account.

d Because Chlorella, Helicosporidium, Leptosira and Stigeoclonium cpDNAs lack an IR, only the total size is given for each of these genomes.

e The gene repertoire of this alga was erroneously reported to include trnl(cau), explaining the difference with the gene number published previously $[3,7,8]$.

f This region was designated SCI by de Cambiaire et al. [8] rather than LSC because it differs markedly in gene content relative to the LSC region in Mesostigma and Nephroselmis cpDNAs.

$\mathrm{g}$ This region was designated SC2 by de Cambiaire et al. [8] rather than SSC because it differs markedly in gene content relative to the SSC region in Mesostigma and Nephroselmis cpDNAs.

The propensity of adjacent genes to be located on the same strand is a property distinguishing all UTC algal cpDNAs, except the Chlorella genome, from Nephroselmis and streptophyte cpDNAs. The degree to which neighbouring genes are clustered on the same strand is reported in Figure 3 for various chlorophyte chloroplast genomes using the sidedness index $\left(\mathrm{C}_{\mathrm{s}}\right)$ of Cui et al. [13]. This index was calculated using the formula $\mathrm{C}_{\mathrm{s}}=\left(n-n_{S B}\right) /(n-1)$, where $n$ is the total number of genes in the genome and $n_{S B}$ is the number of sided blocks, i.e. the number of blocks containing adjacent genes on the same strand. When $\mathrm{C}_{\mathrm{s}}$ reaches the maximum value of 1 , all genes are located on one strand. In Figure 3, it can be seen that the sidedness index of Leptosira cpDNA $\left(\mathrm{C}_{\mathrm{s}}=0.88\right)$ is comparable to those of most other UTC algal cpDNAs. However, in contrast to Stigeoclonium cpDNA and Helicosporidium plastid DNA, analyses of cumulative GC and AT skews indicated that the coding strand bias in the Leptosira genome is not associated with a strand bias in base composition.

\section{Gene order}

Unlike its Chlorella homologue, the Leptosira chloroplast genome does not reveal any obvious remnant of the ancestral gene partitioning pattern displayed by Nephroselmis and most streptophyte cpDNAs (Figure 1). However, the two trebouxiophyte genomes resemble one another with respect to the conservation of ancestral gene clusters (Figure 4). Leptosira cpDNA exhibits nine of the 24 ancestral clusters conserved between Mesostigma and Nephroselmis cpDNAs as well as the remains of five other clusters; altogether, these conserved clusters encode 53 genes. In Chlorella, 62 genes are found to be part of 11 intact and four partially conserved, ancestral clusters. Breakage of three of the intact clusters present in Chlorella cpDNA, further fragmentation of the four partially conserved clusters in this alga and specific retention of an ancestral cluster [ $r$ pl20-trnD (guc] absent from the Chlorella and other UTC cPDNAs explain the main differences observed in the Leptosira genome. Note that these rearrangement events involved the disruption of the highly conserved rRNA operon [rrs-trnI(gau)-trnA(ugc)-rrl-rrf] downstream of $r r s$ and the relocalization of this gene 62 $\mathrm{kb}$ away from the remaining portion of the operon.

Only two derived gene clusters, $\operatorname{trn} V(\mathrm{uac})-\operatorname{trn} L(\mathrm{caa})$ and rpl20-rps18, are shared specifically between Leptosira and Chlorella cpDNAs. The rpl20-rps18 gene pair is also conserved in the ulvophytes Oltmannsiellopsis and Pseudendoclonium.

To compare the degrees of similarity in gene order between the Leptosira and other green algal cpDNAs, we also estimated the minimal number of gene permutations that would be required to convert the gene order of a given genome to that of another genome. More specifically, we examined the orders of the 86 genes common to the cpDNAs of Leptosira, Chlorella, Nephroselmis, Oltmannsiellopsis, Pseudendoclonium, Stigeoclonium, Scenedesmus and Chlamydomonas using GRIMM [19]. We found that the Leptosira and Chlorella genomes differ by as many as 53 inversions. As shown in Table 2, this level of gene rearrangements is identical to that found for the cpDNAs of the ulvophytes Oltmannsiellopsis and Pseudendoclonium but 


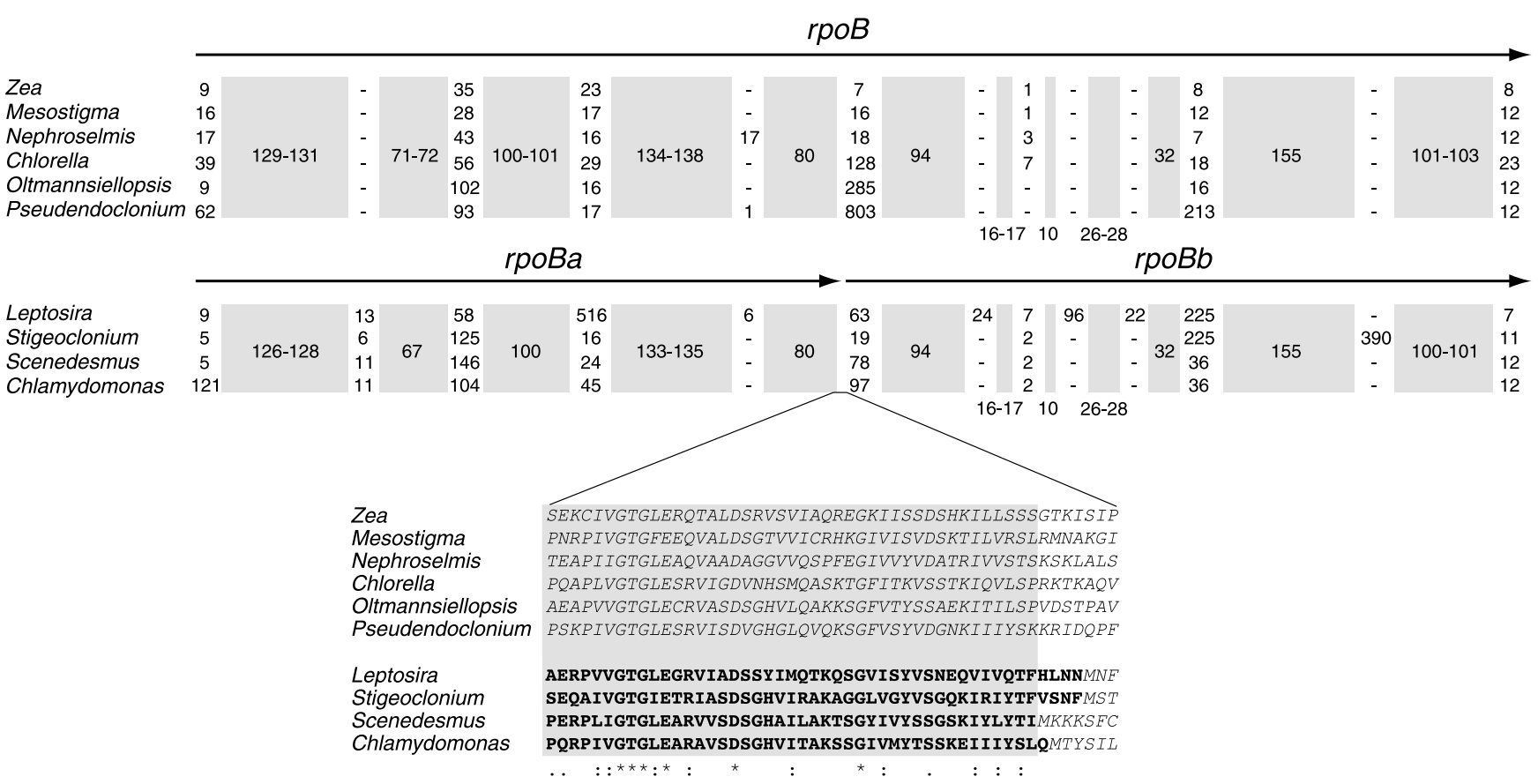

Figure 2

Comparison of the Leptosira RNA polymerase $\beta$ ' subunit with its homologues in other chlorophytes and the streptophytes Mesostigma and maize. The sequences of the rpoB gene products were aligned using the fused rpoBa and rpoBb gene products of Leptosira, Stigeoclonium, Scenedesmus and Chlamydomonas. The regions showing significant sequence conservation are denoted by grey boxes, with the numbers inside these boxes referring to amino acids. The numbers of amino acids in the variable regions are also indicated. The lower portion of the figure shows the alignment for the region corresponding to the junction between the $r p \circ B a$ and $r p o B b$ gene products. The segment showing significant sequence similarity within this region is represented by the grey box. The $\mathrm{C}$-terminal residues of $\mathrm{RpoBa}$ are in bold characters and the $\mathrm{N}$-terminal residues of $\mathrm{RpoBb}$ are in italics.

lower than those obtained for the chlorophycean algae Stigeoclonium, Scenedesmus and Chlamydomonas (59-83 inversions). Furthermore, our results showed that the Nephroselmis, ulvophyte and chlorophycean genomes, except Stigeoclonium cpDNA, display more similarity in gene order with the Chlorella genome than with Leptosira cpDNA.

\section{Intron content}

The four group I introns in Leptosira cpDNA interrupt chlL, $p s a B, p s b C$ and $\operatorname{trnL}$ (uaa). They fall within two different subgroups (IA1 and IC3), with the IA1 subgroup including the three introns found in protein-coding genes. All four introns, except that present in $p s b C$, are positionally and structurally homologous to previously reported introns in chlorophyte cpDNAs (Table 3). In this context, it is worth noting that Leptosira and Chlorella cpDNAs share homologous introns in $\operatorname{trnL}(\mathrm{uaa})$ and $\operatorname{chlL}$. The $p s b C$ intron is unique to Leptosira and displays an ORF. The predicted protein of 415 amino acids specified by this ORF is related to the LAGLIDADG endonucleases and contains two copies of this motif.

\section{Repeated sequences}

Comparison of the Leptosira cpDNA sequence against itself reveals that short repeats are present in many intergenic regions as well as in some introns and genes (predominantly expanded genes) (Figure 5). Repeats represent $5.1 \%$ of the total genome sequence and $8.5 \%$ of the total size of the intergenic regions. The relative abundance of these elements is therefore lower than in Chlorella cpDNA ( $7.8 \%$ of total genome and $14.9 \%$ of intergenic regions) but is comparable to those observed in Scenedesmus and Pseudendoclonium cpDNAs (see Table 2 in [20]). In all other completely sequenced cpDNAs of photosynthetic UTC algae, short repeats account for more than $10 \%$ of the genome. The longest repeated sequence in Leptosira cpDNA is 194 bp in size, whereas the maximal size of the Chlorella repeats is two-fold smaller ( $84 \mathrm{bp}$ ).

The most abundant repeated sequences in the Leptosira genome consist of dispersed repeats. Analysis of these repeats revealed two distinct groups of repeat units: repeat unit A with sequences of 25 bp (TTYAYCTGGGCAGGGAGATYYGRTC) and repeat unit B with sequences of $18 \mathrm{bp}$ 


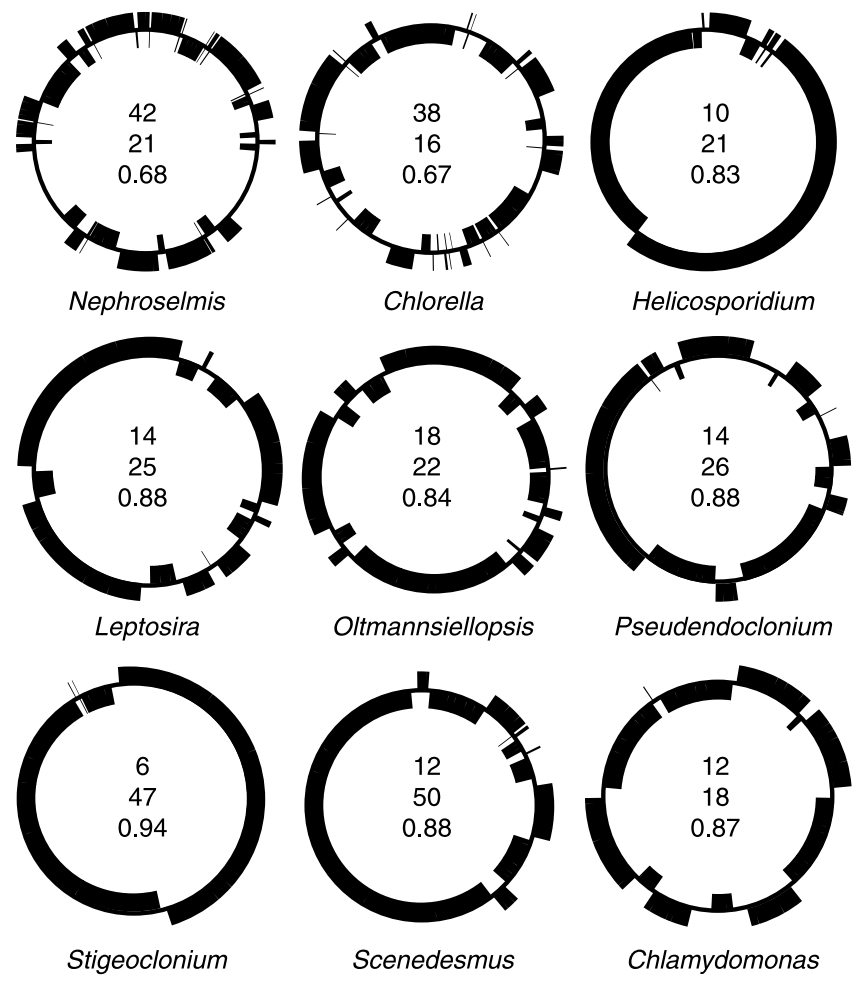

Figure 3

Distributions of genes on the two DNA strands in Leptosira and other green algal cpDNAs. Black boxes denote blocks of adjacent genes on the same DNA strand. For each genome, the total number of gene blocks (top number), the maximum number of genes observed in a block (middle number) and the sidedness index $\mathrm{C}_{\mathrm{s}}$ (bottom number) are indicated.

(CRGTWWATAAATCWWWGA). Each group of repeats features variants that differ slightly in primary sequence. Altogether, the 81 copies of repeat unit A and the 74 copies of repeat unit B represent $1.7 \%$ of the Leptosira genome sequence. In term of localization, a close relationship exists between repeat units A and B. Copies of repeat unit $A$ are frequently found to be contiguous with the reverse complement of an almost identical sequence, creating imperfect palindromes. Copies of repeat unit B, in turn, are usually associated with such palindromes to generate larger palindromes of the type $\mathrm{B}-\mathrm{A}-\mathrm{A}_{\mathrm{rev}}-\mathrm{B}_{\text {rev }}$, where rev stands for reverse complement. No repeats identical to the Leptosira repeat units A and B were detected in any other completely sequenced UTC algal cpDNA.

\section{Discussion \\ Multiple losses of the IR during the evolution of trebouxiophytes}

As in Chlorella vulgaris cpDNA and Helicosporidium plastid DNA, we found that a rDNA-encoding IR is missing from the Leptosira chloroplast genome. Despite the absence of the IR in these three trebouxiophyte DNAs, there is little doubt that the chloroplast genome from the common ancestor of all trebouxiophytes featured a quadripartite structure very similar to that found in streptophytes and the prasinophyte Nephroselmis. This inference is supported by two separate observations. First, the partially sequenced chloroplast genome of Chlorella ellipsoidea, a representative of the trebouxiophyte order Prasiolales, displays a large IR, even though the latter region is atypical in containing a disrupted rDNA operon [21]. Second, the IR-lacking Chlorella vulgaris cpDNA retains not only a remnant of an IR in the form of a pseudo rrs gene [5] but also the ancestral partitioning of genes displayed by prasinophyte cpDNA $[3,10]$.

Although the divergence order of the various monophyletic groups recognized in the Trebouxiophyceae remains ambiguous, the currently available phylogenetic data suggest that at least two distinct events of IR loss account for the disappearance of the IR in the three sequenced trebouxiophyte chloroplast genomes. The Trebouxiophyceae is a morphologically diverse assemblage that includes lichen phycobionts such as Trebouxia, freeliving planktonic or terrestrial species, secondarily nonphotosynthetic coccoid algae and picoplanktonic coccoids $[22,23]$. At least five distinct monophyletic lineages are recovered with $18 \mathrm{~S}$ rDNA data [24-27], four of which

Table 2: Minimal numbers of inversions estimated in pairwise comparisons of gene order in chlorophyte cpDNAs

\begin{tabular}{|c|c|c|c|c|c|c|c|}
\hline \multirow[b]{2}{*}{ Compared cpDNAs } & \multicolumn{7}{|c|}{ Number of inversions a } \\
\hline & Chlorella & Leptosira & Oltmannsiellopsis & Pseudendoclonium & Stigeoclonium & Scenedesmus & Chlamydomonas \\
\hline Nephroselmis & 46 & 51 & 54 & 54 & 79 & 73 & 72 \\
\hline Chlorella & & 53 & 50 & 50 & 78 & 73 & 71 \\
\hline Leptosira & & & 55 & 58 & 77 & 74 & 72 \\
\hline Oltmannsiellopsis & & & & 53 & 81 & 75 & 74 \\
\hline Pseudendoclonium & & & & & 77 & 74 & 73 \\
\hline Stigeoclonium & & & & & & 78 & 83 \\
\hline Scenedesmus & & & & & & & 59 \\
\hline
\end{tabular}

a Numbers of gene permutations by inversions were computed using GRIMM [19]. 
Table 3: Introns in Leptosira cpDNA and homologous introns at identical gene locations in other chlorophyte cpDNAs

\begin{tabular}{|c|c|c|c|c|}
\hline \multicolumn{3}{|c|}{ Leptosira intron } & \multicolumn{2}{|c|}{ Homologous introns } \\
\hline Designation & Subgroup $^{a}$ & ORF location ${ }^{b}$ & Green alga $c /$ Intron number ${ }^{d}$ & Accession no. \\
\hline \multirow[t]{3}{*}{ Lt.trnL(uaa) } & IC3 & - & Bryopsis plumosa $(\mathrm{U})$ & GenBank:M6II59 \\
\hline & & & Chlorella vulgaris $(\mathrm{T})$ & GenBank:NC 001865 \\
\hline & & & Scenedesmus obliquus (C) & GenBank:M9064I \\
\hline Lt.chlL & $|A|$ & - & Chlorella vulgaris $(\mathrm{T})$ & GenBank:NC 001865 \\
\hline \multirow[t]{3}{*}{ Lt.psaB } & $|A|$ & - & Chlamydomonas moewusii (C) & GenBank:M9064I \\
\hline & & & Scenedesmus obliquus (C) & GenBank:M9064I \\
\hline & & & Stigeoclonium helveticum i2 (C) & Genbank:DQ63052I \\
\hline Lt.psbC & $|A|$ & L9.3 & - & - \\
\hline
\end{tabular}

a Group I introns were classified according to Michel and Westhof [48].

${ }^{b} L$ followed by a number refers to the loop extending the base-paired region identified by the number.

c The letter in parentheses denotes the chlorophyte lineage comprising the green alga indicated: U, Ulvophyceae; T, Trebouxiophyceae; C, Chlorophyceae.

${ }^{d}$ The intron number is given when more than one intron is present.

correspond to the Trebouxiales, Microthamniales, Prasiolales and Chlorellales. Members of the Chlorellales, which include both Chlorella vulgaris and Helicosporidium, are consistently identified with high bootstrap support as the earliest-diverging branch of the Trebouxiophyceae, but the interrelationships among the remaining trebouxiophyte lineages remain ambiguous. This tree topology supports the view that the IR was lost independently in the Chlorellales and in the lineage leading to Leptosira. Obviously, for the Chlorellales, a single loss event is the most parsimonious explanation for the absence of the IR in Chlorella vulgaris cpDNA and Helicosporidium plastid DNA. To distinguish this scenario from the alternative hypothesis involving two independent losses, additional members of the Chlorellales will need to be surveyed for the presence/absence of this repeat.

In the light of previous reports indicating that loss of the chloroplast IR occurred relatively frequently during the evolution of the Viridiplantae, our inference that the IR was lost independently on at least two separate occasions in the Trebouxiophyceae does not imply that the quadripartite structure is less unstable in this algal group than in others. Aside from the Trebouxiophyceae, chloroplast genomes that experienced complete or almost-complete loss of the IR have been documented for the chlorophyte classes Ulvophyceae [28] and Chlorophyceae [7], for the charophycean lineage leading to the Zygnematales $[29,30]$ and for a number of land plants, including conifers and six tribes of legumes $[31,32]$. Losses of the IR in conifers and legumes occurred independently and differed in the extent of the IR sequence lost, in the gene content of the IR prior to loss, and in the copy of the IR that was deleted [32]. The site of deletion in pea cpDNA was found to exhibit duplicated gene fragments, but no simple mechanism involving recombination between these repeats could be postulated to account for the IR loss [33].
In the present study, it was not possible to elaborate evolutionary models for the IR losses sustained by green algal cpDNAs, because the highly variable gene organization found in these genomes precluded inferences of gene order in ancestral IR-containing cpDNAs. Chloroplast genome sequences from more trebouxiophytes will thus be required to gain deeper insight into how the IR was deleted.

\section{Similar evolutionary forces may have shaped the IR- lacking Leptosira and Stigeoclonium chloroplast genomes}

We found that the Leptosira chloroplast genome differs considerably from its Chlorella vulgaris counterpart not only in gene order, but also in gene density, gene distribution between the two DNA strands and structure of some protein-coding genes. The important changes in gene order (Table 2) and in conservation level of ancestral gene clusters (Figure 4) observed for these trebouxiophyte cpDNAs are not surprising, given that IR loss is generally correlated with gene rearrangements $[11,12]$. On the basis of this correlation, it has been hypothesized that IR loss enhances the frequency of intramolecular recombination between short dispersed repeats [31]. In this context, it is worth mentioning that no short dispersed repeats $=30 \mathrm{bp}$ with over $90 \%$ sequence identity are shared between the intergenic regions of Leptosira and Chlorella vulgaris cpDNAs, suggesting that these elements evolved independently in these two trebouxiophyte lineages. The fact that the Chlorella vulgaris genome displays a more ancestral gene order than its Leptosira homologue might be due to a more recent loss of the IR and/or a more recent proliferation of short repeats in the Chlorella vulgaris lineage.

Most intriguingly, the Leptosira chloroplast genome exhibits derived traits that are reminiscent of the evolutionary pattern observed for ulvophyte and/or chlorophycean 


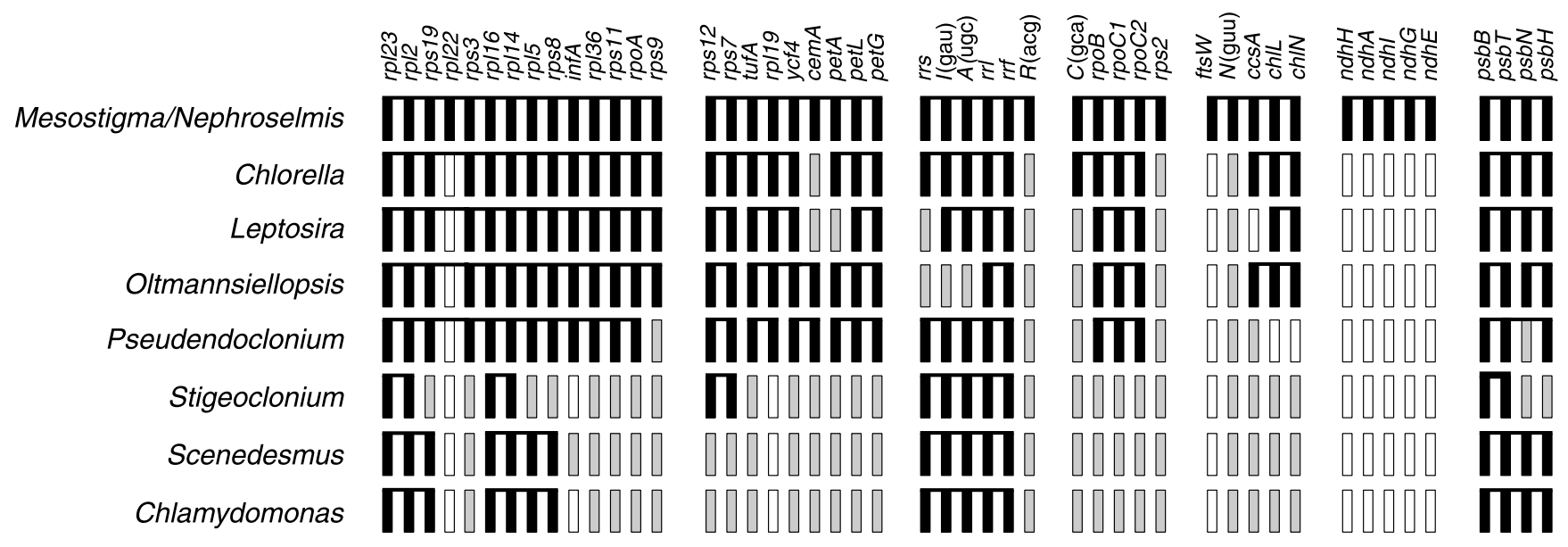

Mesostigma/Nephroselmis
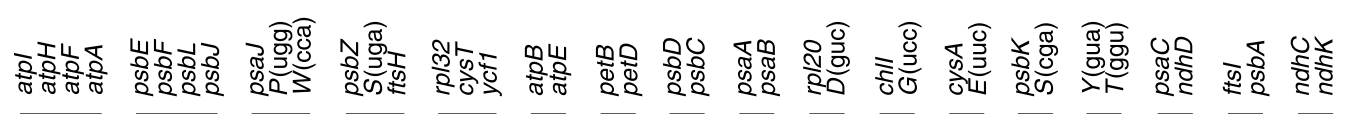

Chlorella
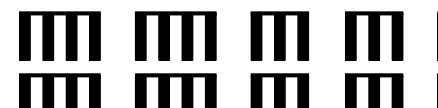

m II
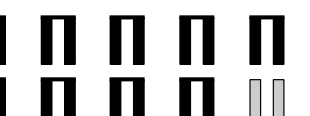

Leptosira

III III $\square$

Oltmannsiellopsis

Pseudendoclonium

III III $\square$
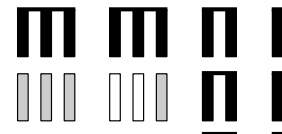

П П П

III ПII $\llbracket \llbracket$

Stigeoclonium

Scenedesmus

Chlamydomonas
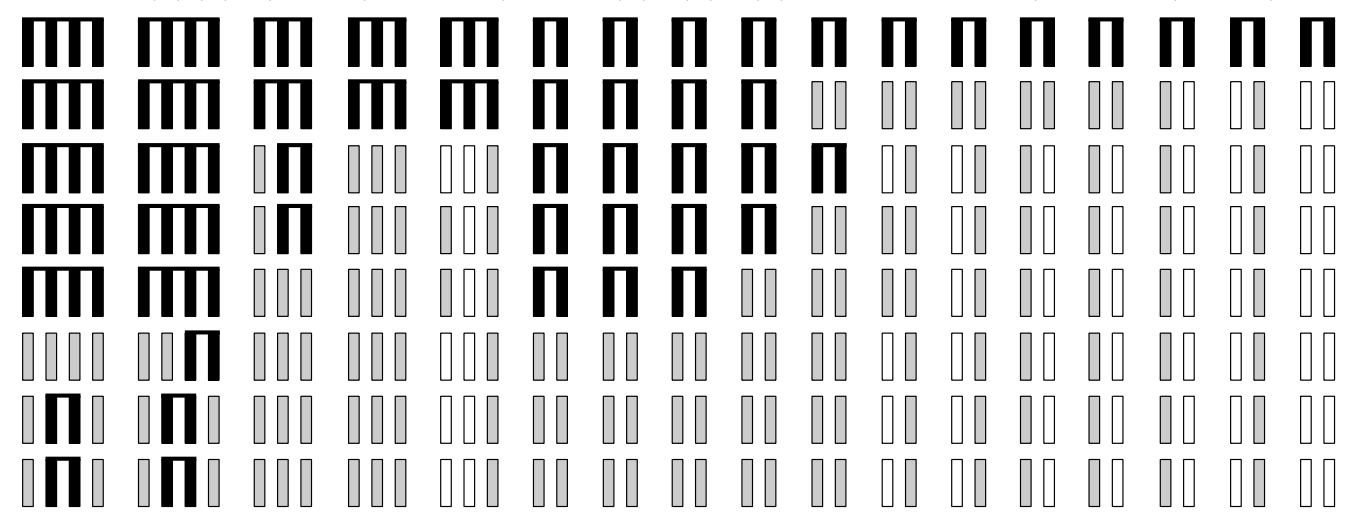

Figure 4

Conservation of ancestral gene clusters in Leptosira and other UTC algal cpDNAs. Black boxes represent the 89 genes found in the 24 clusters shared by Mesostigma and Nephroselmis cpDNAs as well as the genes in UTC algal cpDNAs that have retained the same order as those in these ancestral clusters. For each genome, the set of genes making up each of the identified clusters (either an intact or a fragmented ancestral cluster) is shown as black boxes connected by a horizontal line. Black boxes that are contiguous but are unlinked indicate that the corresponding genes are not adjacent on the genome. Grey boxes denote individual genes that have been relocated on the chloroplast genome; open boxes denote genes that have disappeared from the chloroplast genome. Although the rpl22 gene is missing from Nephroselmis cpDNA, it is shown as belonging to the ribosomal protein cluster equivalent to the contiguous $S 10$, spc and $\alpha$ operons of Escherichia coli because it is present in this cluster in the cpDNAs of Mesostigma, streptophytes and algae from other lineages. Note also that the psbB cluster of Pseudendoclonium differs from the ancestral cluster by the presence of $p s b N$ on the alternate DNA strand.

cpDNAs. These derived traits were identified in the course of analyzing the following genomic features: (1) gene distribution over the two DNA strands, (2) gene density and (3) expansion and structure of protein-coding genes. The Leptosira chloroplast genes display a highly biased and asymmetrical distribution pattern over the two DNA strands, which most closely matches that observed for the chloroplast genome of the chlorophycean green alga Scenedesmus (Figure 3). The strong propensity of adjacent genes to be located on the same DNA strand in Leptosira cpDNA also mirrors the gene distribution patterns found in the chloroplast/plastid genomes of the two other chlo- rophyceans investigated (Stigeoclonium and Chlamydomonas), the ulvophytes Oltmannsiellopsis and Pseudendoclonium and the trebouxiophyte Helicosporidium. With regard to gene density, Leptosira cpDNA is currently known to be the most loosely packed chlorophyte genome (Table 1), followed by the Chlamydomonas and Stigeoclonium cpDNAs. The chloroplast genes exhibiting expanded coding regions relative to their Nephroselmis and streptophyte homologues are three-times more abundant in Leptosira than in Chlorella vulgaris, with the Leptosira set of nine expanded genes being more similar to those found in ulvophyte genomes with respect to coding content. In 

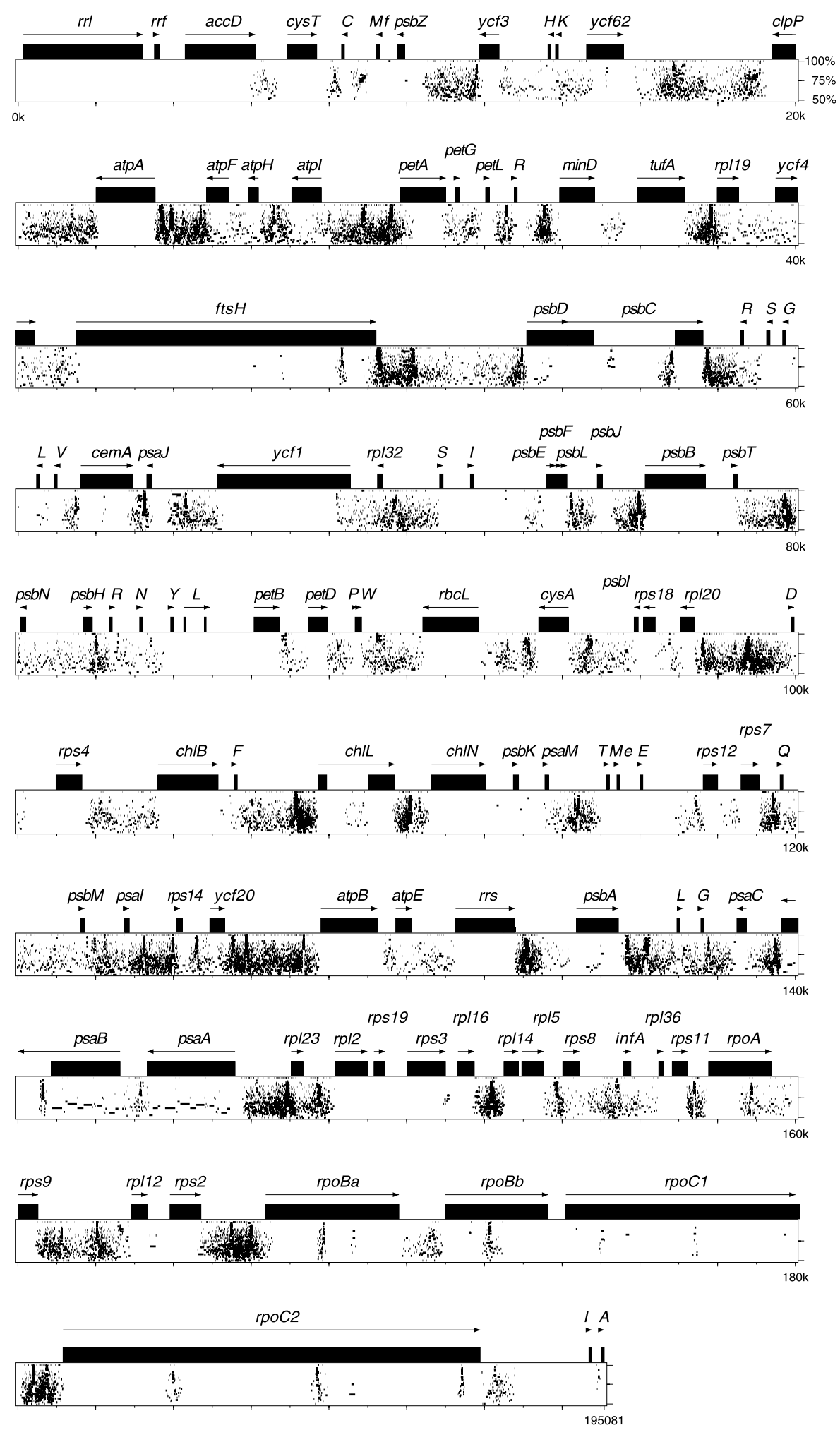

Figure 5

PipMaker analysis of Leptosira cpDNA. The genome sequence was aligned against itself. Similarities between aligned regions are shown as average percent identity (between $50 \%$ and $100 \%$ identity). Genes and their polarities are denoted by horizontal arrows and coding sequences are represented by filled boxes. 
contrast to the conventional structure observed for $r p o B$ in Chlorella vulgaris and ulvophytes, the Leptosira $r p o B$ gene is fractured at the same site as that found for the fragmented genes of the three analyzed chlorophycean green algae (Figure 2). Therefore, two separate events of gene fragmentation, one occurring in the Leptosira lineage and the other before the emergence of the three chlorophycean groups examined so far, must be postulated to account for the distribution of the split $r p o B$ structure among UTC algae.

From the similarities described above, it is tempting to propose that the same evolutionary forces shaped the IRlacking chloroplast genomes in trebouxiophyte and chlorophycean lineages. However, considering the extraordinary fluidity of the chloroplast genome structure in the Chlorophyceae and the fact that no IR-containing chloroplast genomes from close relatives of Leptosira and Stigeoclonium have been investigated, it remains uncertain whether the common trends identified here are directly linked with the convergent events of IR loss that occurred in these chlorophyte lineages. For the Streptophyta, more specifically the zygnematalean lineages leading to Staurastrum and Zygnema, there exists convincing evidence that IR loss from the chloroplast genome was correlated with the expansion of intergenic regions and extensive gene rearrangements [30]. Indeed, the low degree of compaction, the highly scrambled gene order and the numerous disrupted ancestral clusters observed in the Staurastrum and Zygnema genomes contrast sharply with the short intergenic spacers and with the extraordinary conservation of gene order and ancestral clusters exhibited by all their homologues in other streptophyte lineages.

\section{Conclusion}

The numerous derived features that we report here for the IR-lacking Leptosira chloroplast genome contrast sharply with the pronounced degree of ancestral features displayed by Chlorella vulgaris cpDNA, a trebouxiophyte genome also missing a rDNA-encoding IR. The close resemblance of the Leptosira genome with its ulvophyte and/or chlorophycean homologues with respect to the pattern of gene distribution, gene density and structure of protein-coding genes was also an unanticipated finding. On the basis of the current knowledge regarding the phylogeny of trebouxiophytes and the distribution of the presence/absence of the IR in the chloroplast genome, we conclude that the IR was lost independently in the Chorellales and the Leptosira lineage. The intriguing similarities between the derived features exhibited by the Leptosira chloroplast genome and those of its chlorophycean counterparts might suggest that the same evolutionary forces shaped the IR-lacking chloroplast genomes in the Leptosira and chlorophycean lineages. To test this hypothesis and better understand the dynamics of IR loss, IR-containing chloroplast genomes from close relatives of Leptosira and Stigeoclonium will need to be investigated.

\section{Methods}

\section{Isolation and sequencing of Leptosira cpDNA}

Leptosira terrestris (formally Pleurastrum terrestre Fritsch et John) was obtained from the University of Texas Algal Culture collection (UTEX 333) and grown in modified Volvox medium [34] under 12 h light-dark cycles. An A+T rich fraction containing cpDNA was isolated and sequenced as previously described [35]. Sequences were assembled and edited with SEQUENCHER 4.2 (Gene Codes Corporation, Ann Harbor, MI). The fully annotated genome sequence has been deposited in [GenBank:EF506945].

\section{Sequence analyses}

Genes were identified by BLAST searches [36] against the nonredundant database of the National Center for Biotechnology Information server (NCBI) [37]. Positions of ORFs and protein coding genes were determined using ORFFINDER at NCBI, programs of the GCG Wisconsin package (version 10.3) (Accelrys, San Diego, CA, USA) and applications from the EMBOSS version 2.9.0 package [38]. Gene coding for tRNAs were localized with tRNAscan-SE 1.23 [39]. The RpoB sequences were aligned using ClustalW 1.82 [40]. Repeated sequences were identified with PipMaker [41] and REPuter 2.74 [42]. Repeats were sorted with REPEATFINDER [43] and the retrieved classification was refined manually. Numbers of SDR units were determined with FINDPATTERNS of the GCG Wisconsin package version 10.3. The total length of genome sequences containing repeated elements was estimated with RepeatMasker [44] running under the WU-BLAST 2.0 search engine [45]. Separate files containing the concatenated sequences of the intergenic regions of Leptosira and Chlorella cpDNAs were produced to search for the presence of shared repeated elements $=30 \mathrm{bp}$ with up to $10 \%$ mismatches using the $-d-p-l 30-e \quad 3$-seedlength $10-q-v$ options of $\mathrm{V}$ match [46]. The results of this analysis were visualized using GenAlyzer 0.81b [47].

\section{Analyses of genome rearrangements}

The GRIMM web server [19] was used to infer the minimal number of gene permutations by inversions in pairwise comparisons of chloroplast genomes. For these analyses, genes within one of the two copies of the IR were excluded from the data set and only the genes common to all compared genomes were analyzed. The data set used in the comparative analyses reported in Table 2 contained 86 genes; the three exons of the trans-spliced $p s a A$ and $r b c L$ genes, the two exons of the trans-spliced $p s a C$ and petD genes, as well as the $r p o B a$ and $r p o B b$ genes, were coded as distinct fragments (for a total of 93 loci). 


\section{Authors' contributions}

JCdC participated in the conception of this study, carried out part of the genome sequencing, performed all sequence analyses, annotated the genome, generated the tables and figures and drafted the manuscript. CO participated in the sequencing and contributed to the assembly of the genome sequence. CL and MT conceived and supervised the study, contributed to the interpretation of the data and prepared the manuscript. All authors read and approved the final manuscript.

\section{Acknowledgements}

This work was supported by a grant from the Natural Sciences and Engineering Research Council of Canada (to CL and MT).

\section{References}

I. Turmel M, Otis C, Lemieux C: The chloroplast genome sequence of Chara vulgaris sheds new light into the closest green algal relatives of land plants. Mol Biol Evol 2006, 23(6): 1324-1338.

2. Turmel M, Pombert JF, Charlebois P, Otis C, Lemieux C: The green algal ancestry of land plants as revealed by the chloroplast genome. Int $J$ Plant Sci 2007, 168(5):679-689.

3. Pombert JF, Lemieux C. Turmel M: The complete chloroplast DNA sequence of the green alga Oltmannsiellopsis viridis reveals a distinctive quadripartite architecture in the chloroplast genome of early diverging ulvophytes. BMC Biology 2006, 4:3.

4. Pombert JF, Otis C, Lemieux C, Turmel M: The chloroplast genome sequence of the green alga Pseudendoclonium akinetum (Ulvophyceae) reveals unusual structural features and new insights into the branching order of chlorophyte lineages. Mol Biol Evol 2005, 22(9): 1903-19|8.

5. Wakasugi T, Nagai T, Kapoor M, Sugita M, Ito $M$, Ito $S$, Tsudzuki J, Nakashima K, Tsudzuki T, Suzuki Y, Hamada A, Ohta T, Inamura A, Yoshinaga K, Sugiura M: Complete nucleotide sequence of the chloroplast genome from the green alga Chlorella vulgaris: the existence of genes possibly involved in chloroplast division. Proc Natl Acad Sci USA 1997, 94(I I):5967-5972.

6. de Koning AP, Keeling PJ: The complete plastid genome sequence of the parasitic green alga Helicosporidium sp. is highly reduced and structured. $B M C$ Biology 2006, 4: 12 .

7. Bélanger AS, Brouard IS, Charlebois $P$, Otis C, Lemieux C, Turmel M: Distinctive architecture of the chloroplast genome in the chlorophycean green alga Stigeoclonium helveticum. Mol Gen Genomics 2006, 276:464-477.

8. de Cambiaire JC, Otis C, Lemieux C, Turmel M: The complete chloroplast genome sequence of the chlorophycean green alga Scenedesmus obliquus reveals a compact gene organization and a biased distribution of genes on the two DNA strands. BMC Evol Biol 2006, 6:37.

9. Maul JE, Lilly JW, Cui L, dePamphilis CW, Miller W, Harris EH, Stern DB: The Chlamydomonas reinhardtii plastid chromosome: islands of genes in a sea of repeats. The Plant cell 2002, I 4(I I):2659-2679.

10. Turmel M, Otis C, Lemieux C: The complete chloroplast DNA sequence of the green alga Nephroselmis olivacea: insights into the architecture of ancestral chloroplast genomes. Proc Natl Acad Sci USA 1999, 96: 10248-10253.

11. Palmer JD, Osorio B, Aldrich J, Thompson WF: Chloroplast DNA evolution among legumes: Loss of a large inverted repeat occurred prior to other sequence rearrangements. Curr Genet 1987, II:275-286.

12. Strauss SH, Palmer JD, Howe GT, Doerksen AH: Chloroplast genomes of two conifers lack a large inverted repeat and are extensively rearranged. Proc Natl Acad Sci USA 1988, 85:3898-3902.

13. Cui L, Leebens-Mack J, Wang LS, Tang J, Rymarquis L, Stern DB, dePamphilis CW: Adaptive evolution of chloroplast genome structure inferred using a parametric bootstrap approach. BMC Evol Biol 2006, 6: I3.
14. Friedl T: Evolution of the polyphyletic genus Pleurastrum (Chlorophyta): inferences from nuclear-encoded ribosomal DNA sequences and motile cell ultrastructure. Phycologia 1996, 35:456-469.

15. Lilly JW, Maul JE, Stern DB: The Chlamydomonas reinhardtii organellar genomes respond transcriptionally and post-transcriptionally to abiotic stimuli. The Plant cell 2002, I 4( I I ):268I-2706

16. Bergsland $\mathrm{KJ}$, Haselkorn R: Evolutionary relationships among eubacteria, cyanobacteria, and chloroplasts: evidence from the rpoCI gene of Anabaena sp. strain PCC 7I20. Journal of bacteriology |99I, I73(II):3446-3455.

17. Perler FB: InBase: the Intein Database. Nucleic acids research 2002, 30(I):383-384

18. InBase, The Intein Database and Registry [http:// www.neb.com/neb/inteins.html]

19. Tesler G: GRIMM: genome rearrangements web server. Bioinformatics 2002, I 8:492-493.

20. Lemieux C, Otis C, Turmel M: A clade uniting the green algae Mesostigma viride and Chlorokybus atmophyticus represents the deepest branch of the Streptophyta in chloroplast genome-based phylogenies. BMC Biology 2007, 5:2.

21. Yamada T: Repetitive sequence-mediated rearrangements in Chlorella ellipsoidea chloroplast DNA: completion of nucleotide sequence of the large inverted repeat. Curr Genet 1991, I9(2): |39-| 48.

22. Friedl T: The evolution of the green algae. PI Syst Evol (Suppl) 1997, I I:87-101.

23. Lewis LA, McCourt RM: Green algae and the origin of land plants. Am J Bot 2004, 9 I (I0): I535-1556.

24. Friedl T, O'Kelly C): Phylogenetic relationships of green algae assigned to the genus Planophila (Chlorophyta): evidence from I 85 rDNA sequence data and ultrastructure. Eur J Phycol 2002, 37:373-384.

25. Henley WJ, Hironaka JL, Guillou L, Buchheim MA, Buchheim JA, Fawley MW, Fawley KP: Phylogenetic analysis of the 'Nannochlorislike' algae and diagnoses of Picochlorum oklahomensis gen. et sp. nov. (Trebouxiophyceae, Chlorophyta). Phycologia 2004, 43(6):64I-652.

26. Karsten U, Friedl T, Schumann R, Hoyer K, Lembcke $S$ Mycosporine-like amino acids and phylogenies in green algae: Prasiola and its relatives from the Trebouxiophyceae (Chlorophyta). J Phycol 2005, 4I:557-566.

27. Krienitz L, Hegewald EH, Hepperle D, Huss VAR, Rohr T, Wolf M: Phylogenetic relationship of Chlorella and Parachlorella gen. nov. (Chlorophyta, Trebouxiophyceae). Phycologia 2004, 43(5):529-542.

28. Manhart JR, Kelly K, Dudock BS, Palmer JD: Unusual characteristics of Codium fragile chloroplast DNA revealed by physical and gene mapping. Mol Gen Genet I989, 216(2-3):417-42I.

29. Manhart JR, Hoshaw RW, Palmer JD: Unique chloroplast genome in Spirogyra maxima (Chlorophyta) revealed by physical and gene mapping. J Phycol 1990, 26:490-494.

30. Turmel M, Otis C, Lemieux C: The complete chloroplast DNA sequences of the charophycean green algae Staurastrum and Zygnema reveal that the chloroplast genome underwent extensive changes during the evolution of the Zygnematales. BMC Biology 2005, 3:22.

31. Palmer JD: Plastid chromosomes: structure and evolution. In The Molecular Biology of Plastids Edited by: Bogorad L, Vasil K. San Diego , Academic Press; 1991:5-53.

32. Raubeson LA, Jansen RK: Chloroplast genomes of plants. In Plant Diversity and Evolution: Genotypic and Phenotypic Variation in Higher Plants Edited by: Henry RJ. Wallingford, CABI Publishing; 2005:45-68.

33. Wolfe $\mathrm{KH}$ : The site of deletion of the inverted repeat in pea chloroplast DNA contains duplicated gene fragments. Current Genetics 1988, I3(I):97-100.

34. McCracken DA, Nadakavukaren MJ, Cain JR: A biochemical and ultrastructural evaluation of the taxonomic position of Glaucosphaera vacuolata Korsch. New Phytol 1980, 86:39-44.

35. Pombert JF, Otis C, Lemieux C, Turmel M: The complete mitochondrial DNA sequence of the green alga Pseudendoclonium akinetum (Ulvophyceae) highlights distinctive evolutionary trends in the Chlorophyta and suggests a sistergroup relationship between the Ulvophyceae and Chlorophyceae. Mol Biol Evol 2004, 2 I(5):922-935. 
36. Altschul SF, Gish W, Miller W, Myers EW, Lipman DJ: Basic local alignment search tool. J Mol Biol 1990, 21 5:403-4I0.

37. Basic Local Alignment Search Tool at NCBI [http:// www.ncbi.nlm.nih.gov/BLAST/]

38. Rice P, Longden I, Bleasby A: EMBOSS: the European Molecular Biology Open Software Suite. Trends Genet 2000, 16(6):276-277.

39. Lowe TM, Eddy SR: tRNAscan-SE: a program for improved detection of transfer RNA genes in genomic sequence. Nucleic Acids Res 1997, 25:955-964.

40. Thompson JD, Higgins DG, Gibson TJ: CLUSTAL W: improving the sensitivity of progressive multiple sequence alignment through sequence weighting, position-specific gap penalties and weight matrix choice. Nucleic Acids Res 1994, 22(22):4673-4680.

41. Schwartz S, Zhang Z, Frazer K, Smit A, Riemer C, Bouck J, Gibbs R, Hardison R, Miller W: PipMaker: a web server for aligning two genomic DNA sequences. Genome Res 2000, 10:577-586.

42. Kurtz S, Choudhuri JV, Ohlebusch E, Schleiermacher C, Stoye J, Giegerich R: REPuter: the manifold applications of repeat analysis on a genomic scale. Nucleic Acids Res 200I, 29(22):4633-4642.

43. Volfovsky N, Haas BJ, Salzberg SL: A clustering method for repeat analysis in DNA sequences. Genome Biol 200I, 2(8):0027.I-27.II.

44. RepeatMasker [http://www.repeatmasker.org/]

45. WU-BLAST [http://blast.wustl.edu/]

46. The Vmatch large scale sequence analysis software [http:// www.vmatch.de/]

47. Choudhuri JV, Schleiermacher C, Kurtz S, Giegerich R: GenAlyzer: interactive visualization of sequence similarities between entire genomes. Bioinformatics 2004, 20:1964-1965.

48. Michel F, Westhof E: Modelling of the three-dimensional architecture of group I catalytic introns based on comparative sequence analysis. J Mol Biol 1990, 216(3):585-6I0.

Publish with Bio Med Central and every scientist can read your work free of charge

"BioMed Central will be the most significant development for disseminating the results of biomedical research in our lifetime. "

Sir Paul Nurse, Cancer Research UK

Your research papers will be:

- available free of charge to the entire biomedical community

- peer reviewed and published immediately upon acceptance

- cited in PubMed and archived on PubMed Central

- yours - you keep the copyright

Submit your manuscript here:

http://www.biomedcentral.com/info/publishing_adv.asp
BiolMedcentral 